\title{
A VISITA DOMICILIÁRIA COMO MÉTODO DE ASSISTENCIA DE ENFERMAGEM A FAMILIA
}

\author{
Maria Jacyra de Campos Nogueira* \\ Rosa Maria Godoy Serpa da Fonseca**
}

NOGUEIRA, M. J. C. \& SERPA DA FONSECA, R. M. G. - A visita domiciliária como método de assistência de enfermagem à família. Rev. Esc. Enf., 11(1):28-50, 1977.

Descrevem-se a importância, os objetivos e a metodologia da visita domiciliária, bem como os passos para a organização de serviços de visitação domiciliária em centros de saúde ou hospitais.

\section{IMPORTÂNCIA, VANTAGENS E LIMITAÇÕES DO METODO}

Muito já se tem escrito (1) (3) a respeito da importância da abordagem familiar para a assistência à saúde adequada, salientandose que $o$ ambiente familiar, quer sob os aspectos de relacionamento afetivo-social, quer sob os aspectos físicos, se constitui no conjunto afetivo-social, quer sob os aspectos físicos, se constitui no conjunto das mais poderosas forças que influenciam a promoção, proteção e recuperação da saúde dos indivíduos.

Alguns autores (2) (3), por outro lado, relatam a importância e a assistência de enfermagem ser focalizada na família, especialmente no campo da Saúde Pública.

* Professor Assistente Doutor da disciplina Enfermagem de Saúde Pública da EEUSP.

** Auxiliar de Ensino da disciplina Enfermagem de Saúde Pública da EEUSP. 
A visita domiciliária é um método dos mais eficientes, utilizado pela enfermagem desde há muito tempo, para proporcionar assistência à família (2).

A visita domiciliária, como método de trabalho para a enfermagem junto às famílias, tem as seguintes vantagens:

- proporciona o conhecimento do indivíduo dentro do seu verdadeiro contexto ou meio ambiente, caracterizado pelas condições da habitação, ou pelas relações afetivo-sociais entre os vários membros da família, que são alguns dos importantes fatores a serem identificados para a prestação de assistência integral à saúde;

- facilita a adaptação do planejamento da assistência de enfermagem de acordo com os recursos de que a família dispõe;

- proporciona melhor relacionamento do profissional com a família, por ser o método menos formal e sigiloso em relação aos utilizados nas atividades internas dos serviços de saúde;

- proporciona maior liberdade para os clientes ou pacientes exporem seus problemas, porque o tempo dedicado a eles é bem maior do que o das atividades internas dos serviços.

A visitação domiciliária tem algumas limitações. São elas:

- é um método relativamente caro, comparado com os outros, pois depende da utilização de pessoal treinado e de meios de transporte;

- o rendimento é pequeno em relação a outros métodos, pois é gasto muito tempo não só na execução da visita, como também em locomoção;

- os afazeres das donas de casa podem impedir ou dificultar, às vezes, a prestação desse tipo de assistência. 
2. OBJETIVOS DA VISITA DOMICILIÁRIA

Em linhas gerais, os principais objetivos da visita domiciliária, como método de trabalho da enfermagem, são:

- prestação de cuidados de enfermagem no domicílio, quando esta for conveniente para o paciente, para a família e para o serviço de saúde, quer sob o aspecto econômico, social ou psicológico;

— orientação a um ou mais membros da família para a prestação de cuidados no domicílio;

- supervisão dos cuidados delegados à família;

- orientação da família em assuntos de higiene em geral, quando o ambiente do serviço de saúde não é o mais adequado, pois as condições não são as mesmas;

- coleta de informações sobre as condições sócio-sanitárias da família, por meio de entrevista e observação.

\section{METODOLOGIA DA VISITAÇÃO DOMICILIÁRIA}

A visita domiciliária se constitui de fases que se sucedem, sem que, na prática, haja uma delimitação muito precisa entre elas. Com a finalidade de sistematização, entretanto, podemos dividir a visita domiciliária em quatro fases: planejamento, execução, registro de dados e avaliação, como ilustramos no esquema a seguir. 


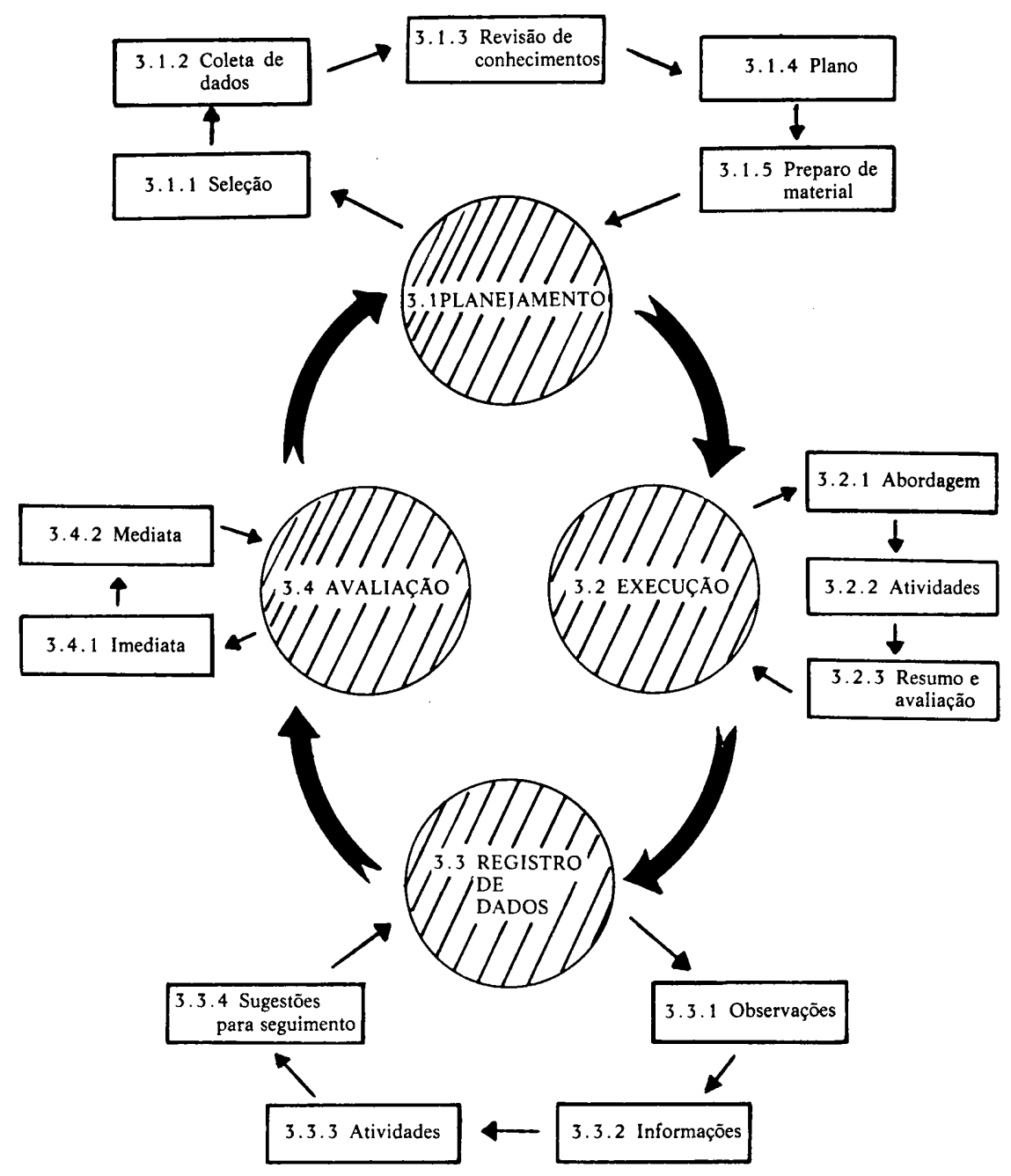




\subsection{PLANEJAMENTO}

Para maior rendimento e objetividade, a visita domiciliária deve ser bem planejada. O planejamento deverá incluir:

\subsubsection{Seleção das visitas a serem realizadas}

Geralmente o pessoal dos serviços de visitação domiciliária, faz várias visitas durante uma jornada de trabalho. $\mathrm{O}$ primeiro passo do planejamento será, portanto, a seleção das visitas a serem realizadas naquele período.

Para a seleção das visitas, além das prioridades baseadas nas necessidades da família e do serviço, deve-se levar em conta o itinerário, o tempo a ser gasto em cada visita e o horário mais adequado para cada família.

E interessante que se considere o itinerário ao se fazer a seleção das visitas, a fim de que não seja dispendido mais tempo na locomoção do visitador do que na sua atividade junto à família.

Quanto à ordem das visitas, prioritariamente, deve-se fazer aquelas em que se gastará menos tempo e, por último, em que se gastará mais tempo. Os casos de doenças transmissíveis devem ser deixadas por último, principalmente os de disseminação por via respiratória, para que não haja perigo do profissional tornar-se um portador temporário e transmitir a doença para as outras famílias a serem visitadas.

Quanto ao tempo gasto èm cada visita, só o tipo de atividade a ser executada durante a sua execução é que poderá determiná-lo. Geralmente na execução de uma visita simples, cujo objetivo é, por exemplo, o de colher alguns dados ou apenas prestar uma informação ou orientação sumária, sem prestação de qualquer outro tipo de cuidado, o visitador leva, em média, trinta minutos. Já quando a visita inclui alguma demonstração ou a execução de algum cuidado a um paciente acamado, pode-se gastar de uma a duas horas.

O horário das visitas deve, se possível, ser discutido e aprovado pela família, que dirá, então, o que lhe é mais adequado, sem, 
contudo, que isso prejudique o bom andamento do serviço. Se isso não for possível, devem, de preferência, ser escolhidos horários que não interrompam os afazeres domésticos.

\subsubsection{Coleta de dados}

Os dados referentes à família a ser visitada podem ser obtidos através dos prontuários ou da informação dos profissionais que já cuidaram, ou cuidam ainda, de algum membro ou de toda a família. Devem-se selecionar apenas os dados mais importantes para a visita em questão.

\subsubsection{Revisão de conhecimentos}

Para um serviço de enfermagem responsável pela visitação domiciliária, em hospitais ou centros de saúde, convergem pedidos de vários outros serviços, da própria unidade sanitária, cujos pacientes possuem os mais variados problemas. A família, por outro lado, é constituída de indivíduos com diferentes idades e diferentes necessidades e problemas. A polivalência, portanto, do pessoal de enfermagem responsável pelas atividades de visitação domiciliária, se faz necessária, para uma assistência familiar adequada.

A revisão dos conhecimentos que a visita requer pode ser feita por meio de leitura de bibliografia ou de outras fontes de informação, tais como os manuais do serviço.

\subsubsection{Plano}

O visitador, como já foi dito, realiza várias visitas num mesmo período de trabalho; portanto, há necessidade de que o visitador tenha consigo, por escrito, os dados mais importantes das famílias a serem visitadas, a fim de que não os esqueça.

Um plano de visita, que inclui esses dados por escrito, facilita ao visitador a manutenção de um bom entrosamento com a família, dando-lhe maior segurança no quie irá falar ou fazer. 
Entretanto, um bom plano não deve ser cópia exata do prontuário do paciente ou de qualquer outra ficha individual ou familiar, mas deve conter os dados essenciais para a execução da visita.

O plano, resumidamente, deverá conter: objetivos geral e específicos; dados gerais - se houver — das condições sócio-sanitárias da família; diagnóstico e tratamentos médicos; dados da assistência de enfermagem prestada; endereço completo e demais dados de identificação da família e atividades a serem executadas.

Um dos aspectos mais importantes a serem considerados nas visitas domiciliárias é a determinação dos seus objetivos, pois a base de um bom planejamento e de sua execução é a definição clara do que se pretende fazer.

Os objetivos da visita domiciliária devem estar de acordo não só com os do serviço de saúde, mas com as necessidades e expectativas da família a ser visitada.

A determinação de objetivos, por outro lado, nem sempre é fácil, principalmente quando se possui poucos dados a respeito da família selecionada. Geralmente o motivo da solicitação da visita domiciliária por um serviço, por um profissional ou pela própria família, é o objetivo geral, principal ou prioritário da visita; os outros, os específicos.

Os objetivos devem, ainda, ser suficientemente flexíveis a ponto de poderem ser mudados de acordo com intercorrências não esperadas, durante a execução da visita.

Um exemplo de um esquema para plano de visita que poderá funcionar como impresso de um serviço, sendo utilizado não só para o registro de dados do planejamento e execução da visita, como também para a avaliação e supervisão, é dado a seguir. 
MODELO DE PLANO DE VISITA DOMICILIÁRIA

N. ${ }^{\circ}$ DE REGISTRO V.D. PEDIDA POR

V.D. FEITA POR DATA ENDEREÇO

CONDIÇŌES SANITARIAS DA HABITAÇÃO: OBJETIVO GERAL:

OBJETIVOS ESPECIFICOS:

\begin{tabular}{|c|c|c|}
\hline $\begin{array}{c}\text { Dados sobre os } \\
\text { membros da família }\end{array}$ & Atividades & $\begin{array}{c}\text { Observações durante } \\
\text { a visita }\end{array}$ \\
\hline
\end{tabular}




\subsubsection{Preparo do material}

O material para o cuidado no domicílio depende dos objetivos e atividades da visita. Poderá ser de tipo educativo ou para tratamentos e cuidados em geral.

Tradicionalmente, o pessoal de enfermagem tem-se utilizado de uma maleta para as visitas, com os seguintes objetivos: facilitar o transporte do material; impedir a sua contaminação e facilitar a prestação de cuidado no domicílio, pois, estando o material à mão, é maior o rendimento da visita domiciliária.

A maleta deverá ser a mais simples possível para facilitar a sua utilização. Deve ser confeccionada com material lavável para facilitar a limpeza.

E interessante, por outro lado, que haja uma padronização na técnica de utilização da mesma, a fim de se obter maior rendimento na execução da visita.

\subsection{EXECUÇÃO}

\subsubsection{Abordagem}

profissional.

A visita domiciliária não é uma atividade social, mas

Às vezes, entretanto, a família ignora as suas finalidades e, se a enfermagem não tomar certos cuidados, a visita poderá tomar um sentido diferente daquele que a caracteriza.

Deve-se levar em conta a forma como o visitador se comporta ao chegar no domicílio, para que a visita não fuja às suas finalidades. Assim, ele não deve se comportar da mesma forma como se comporta com amigos ou familiares ou em outras situações sociais. Isto não quer dizer que ele deva ser rude com a família, a fim de se impor. Deve cultivar a cortesia e não a amizade. Tornando-se íntimo ou amigo das famílias de que cuida ou, dando essa impressão, o visitador poderá levar as famílias a não aceitá-lo mais como profissional do ser- 
viço de saúde e sim como amigo, e as suas orientações poderão até não serem aceitas ou respeitadas.

Por outro lado, ele não deve cair no oposto, tornando a visita extremamente formal, que deixaria, então, de lado uma das vantagens que a caracterizam, que é a de ter uma certa informalidade em relação às outras atividades prestadas pelo serviço de saúde.

Uma forma de não se cair nesses dois tipos extremos, é fazer-se uma abordagem, no início da visita, mais informal, com a finalidade de se estabelecer um relacionamento agradável com a família e, em seguida, passar-se à execução das atividades planejadas.

A abordagem deve incluir uma apresentação à família com a identificação do nome e função do profissional, além da explicação dos objetivos que o trouxeram ao domićlio.

Em seguida, ainda nessa fase, o visitador deve ser amável, sem ser íntimo, e tentar colocar as pessoas à vontade com sua presença (às vezes sentando-se com a dona de casa na cozinha ou ao pé do tanque, se não houver outro local melhor no momento) e, se possível, procurar não interferir nos afazeres domésticos, e nem interrompê-los.

Às vezes, procurando propiciar um clima mais agradável, um dos elementos da família oferece algo para comer ou beber. Não é aconselhável aceitar, a não ser que se perceba que a família poderia se ofender. Isto porque o visitador pode correr o risco de perder tempo, de fugir às finalidades da visita ou ainda se contaminar quando houver, por exemplo, um problema de doença transmissivel na família.

Uma boa explicação a ser dada à família para não aceitar o alimento seria alegar proibição por parte do serviço a que pertence. Outra, pelo fato de não estar acostumado a comer entre as refeições ou ainda que, pelo fato de ter que fazer muitas visitas num só dia, não poderá ficar comendo em todas as casas e prejudicar as refeições.

Uma outra maneira de se estabelecer um bom entrosamento inicial com a família é perguntar sobre a saúde em geral de algum 
membro ausente ou presente mencionando os nomes, quando foi possível obtê-los anteriormente, durante o planejamento da visita.

Um cuidado muito importante que o visitador deve tomar é o de não fornecer os seus dados pessoais, quando a família, querendo manter um entrosamento melhor, começa a fazer perguntas sobre a vida particular do profissional, e a visita poderá, então, fugir aos seus objetivos.

\subsubsection{Atividades}

$\mathrm{Na}$ execução das atividades planejadas para a visita, o visitador deve procurar manter-se dentro dos objetivos tentando controlar interferências externas que poderiam prejudicar a entrevista com um dos membros da família, tais como o aparecimento de vizinhos ou parentes no momento da visitação domiciliária.

O plano elaborado, embora com base numa rigorosa coleta de informações, deve sempre ser adaptado principalmente às emergências que surgirem no momento da sua execução. Isto para que sejam atendidas, de maneira prioritária, as necessidades sentidas, no momento, pela família.

Se o plano tem a finalidade de fornecer, com seus dados, uma visão integral da família, dos seus problemas e necessidades, dando maior segurança à enfermagem e facilitando o seu entrosamento no domicílio, o sucesso da visita dependerá muito, da sua adaptação e, às vezes, até da mudança total de objetivos propostos, quando aparecem as emergâncias.

Existem muitos outros princípios que o profissional deve seguir durante a execução da visita. Dentre eles, temos:

- deixar que as pessoas falem à vontade, exponham seus problemas, mesmo que sejam de natureza diferente dos planejados. Se as pessoas entrevistadas, entretanto, começarem a divagar sobre um assunto que tinham começado a conversar, talvez queiram ocultar alguma coisa sobre o mesmo. Nesse caso, o profissional deverá tentar voltar 
a conversar sobre o assunto que discutiam, pois pode ser referente a algum problema de saúde importante da família;

- respeitar e manter neutralidade acerca de opiniōes, comportamentos, traços culturais, conhecimentos e experiências da família, não demonstrando reações de surpresa, aprovação, desaprovação ou indiferença total, quando qualquer membro dela expressar suas idéias. No caso de ser alguma opinião, comportamento, traço cultural ou conhecimento prejudiciais e em desacordo com as bases científicas das ciências da saúde, o visitador deverá, sutilmente, tentar mudá-los, sem entretanto fazer com que a família se sinta diminuída, errada ou culpada ou, ainda que acreditando estar certa, ela crie barreiras em relação ao profissional de saúde. Quando se trata de opiniões, comportamentos, traços culturais, conhecimentos empíricos mas que não são prejudiciais à saúde, a melhor atitude é respeitá-los e não tentar mudá-los;

- procurar tornar a família o mais independente e responsável possível quanto à execução de ações que visam à promoção, proteção e recuperação da saúde. Para isso, o visitador deve evitar tomar decisões por ela e mostrar apenas as vantagens e desvantagens dos caminhos a serem seguidos além de orientar para a adequada utilização de recursos da própria família e da comunidade;

- aplicar os princípios fundamentais do cuidado de enfermagem sempre adaptados aos recursos da família;

- observar os princípios utilizados no ensino e aprendizagem e na técnica de entrevista, tais como: utilizar vocabulário adequado ao nível de compreensão das pessoas; organizar e dosar o conteúdo do assunto a ser transmitido, não se preocupando em utilizar a visita para ensinar tudo de uma só vez, mas selecionar o que é prioritário no momento; antes de ensinar qualquer assunto, verificar, por meio de perguntas, o que as pessoas já sabem sobre o mesmo; fazer perguntas claras e objetivas, tendo o cuidado para que estas não sugiram respostas;

- observar, enquanto conversa ou executa algum cuidado, o que ocorre ao redor, com as pessoas e o meio ambiente a fim de, se for constatado algum problema prioritário, adaptar os objetivos da visita 
à solução deles; cronometrar o tempo e, se for observado qualquer problema de ordem familiar que atrapalhe a visita ou vice-versa, interromper a mesma, deixando as orientações e cuidados não prioritários, para outra oportunidade;

- evitar tomar notas durante a visita, principalmente se estiver entrevistando alguém, pois há o inconveniente de inibir o entrevistado ou ainda de dificultar a observação do ambiente. Todavia, quando a visita tem como objetivo a coleta de dados da família e o registro imediato se faz necessário, deve-se sempre explicar às pessoas o motivo e o sentido confidencial dos mesmos.

\subsubsection{Resumo e avaliação}

Mesmo que a orientação da enfermagem seja objetiva, que o seu conteúdo seja dosado e bem apresentado, os cuidados que o visitador tem muitas vezes que dispensar no lar e ainda mais as distrações que, por mais que controle, acabam sempre ocorrendo, dispersam a atenção da família para o que é mais importante a ser executado.

Por outro lado pode haver, por parte da família, ainda alguma dúvida a respeito de algum aspecto das orientações.

Por esses motivos, faz-se necessária uma avaliação por meio de perguntas do que foi orientado, além de um resumo dos pontos principais.

Ao se despedir da família o visitador deve deixar claro que procurará atender em outras ocasiões, sempre que puder, a qualquer solicitação de auxílio.

\subsection{REGISTRO DE DADOS}

O registro de dados da visita domiciliária tem como objetivo favorecer e orientar a continuidade do trabalho.

Para que preencha suas finalidades, o registro deve ser feito da seguinte forma: 
- deve conter apenas informações objetivas, que descrevam a situação ou o fato como se apresentou ou aconteceu durante a visita, e não julgamentos do profissional sobre os mesmos. As vezes, para maior fidedignidade, transcreve-se, entre aspas, as próprias palavras usadas pelo entrevistado;

- deve ser claro, não contendo expressões indefinidas ou vagas, abreviações particulares e letra ilegível;

- deve mostrar continuidade com relação a relatórios anteriores para que sirva de instrumento para avaliação do trabalho realizado com a família;

- deve ser resumido e ter uma seqüência lógica para facilitar a leitura e a compreensão dos aspectos mais importantes. Os fatos não devem, de preferência, ser descritos na sequiência em que ocorreram, pois, isso tornará o relatório muito extenso. Para isso, a sequiência lógica do registro de dados ou relatório da visita, nos serviços, poderá ser padronizada, segundo uma seqüência, como por exemplo: observações feitas pelo visitador a respeito da situação encontrada no lar; aparência, atitudes da família; necessidades de saúde atuais e mudanças ocorridas desde a última visita ou desde um outro atendimento pelo serviço de saúde; informações prestadas pela própria família ou por outros parentes ou vizinhos, a respeito dela; atividades desenvolvidas durante a visita, tais como cuidados, orientações, encaminhamentos e, finalmente, de forma resumida, os planos futuros para seguimento.

\subsection{AVALIAÇÃO}

A avaliação da visita domiciliária tem como objetivo verificar se o método planejado para prestação de cuidados à família foi o mais adequado, se o visitador utilizou corretamente os princípios fundamentais da metodologia da visita domiciliária, se a visita atingiu os seus 
objetivos e, ainda, verificar o progresso da família na resolução dos seus problemas.

Alguns desses aspectos, como por exemplo a auto-avaliação do profissional no que diz à utilização dos princípios fundamentais da visita domiciliária, podem ser realizados imediatamente após a visita, no serviço, quando o mesmo for proceder ao registro de dados.

Outros aspectos só poderão ser verificados em épocas mais tardias (avaliação mediata), por meio de relatórios de posteriores comparecimentos da família ao serviço ou após a realização de novas visitas.

Um serviço pode ter, para facilitar a auto-avaliação da enfermagem, um roteiro com itens correspondentes aos princípios fundamentais da visita domiciliária (modelo em anexo 3 ).

\section{ORGANIZAÇÃO DAS ATIVIDADES OU SERVIÇOS DE VISITAÇÃO DOMICILIÁRIA}

A visitação domiciliária pode ser utilizada, como método de proporcionar assistência de enfermagem à família, tanto em hospitais, como em centros de saúde.

Para que os resultados da utilização desse método sejam compensatórios, há a necessidade de serem organizados, corretamente, o serviço ou as atividades de visitação.

Esta organização, segue as seguintes fases: planejamento, execução e avaliação.

O planejamento deve ter as seguintes etapas:

- conhecimento, por meio de levantamento, das condições sócio-sanitárias da população a ser atendida, das suas aspirações e necessidades, dos objetivos e finalidades do serviço de saúde que irá prestar assistência domiciliária (roteiro em anexo 1); 
- elaboração do programa de enfermagem a ser desenvolvido e organização do serviço ou atividades de visitação (roteiro em anexo 2);

- aprovação do programa;

— implantação do serviço ou das atividades.

A execução do programa de visitação domiciliária deve ser acompanhada, constantemente, de avaliação e o programa deve ser periodicamente ajustado ou modificado, de acordo com as necessidades apontadas pela avaliação.

NOGUEIRA, M. J. C. \& SERPA DA FONSECA, R. M. G. - The home visit as nursing assistance method for the family. Rev. Esc. Enf. USP, 11(1):28-50, 1977.

Describes the importance, the goas and the methodology of home visit, as well as the steps for the home visiting services organization in health centers or hospitals.

\section{REFERENCIAS BIBLIOGRÁFICAS}

1. DUNN, H. L. \& GILBERT, M. - Public health begin in family. Publ. Health. Rep., 71(10):1002-1011, oct. 1956.

2. FREEMAN, R. - Enfermería de Salud Publica. México, Interamericana, 1971.

3. NOGUEIRA, M. J. C. - Assistência de enfermagem à família. Enf. Novas Dimens., 3, 1977 (no prelo). 


\section{ANEXO 1 \\ PLANEJAMENTO DO SERVIÇO OU ATIVIDADES DE VISITAÇÃO DOMICILIÁRIA}

Roteiro para levantamento das características da população e do serviço*

\begin{tabular}{|c|c|}
\hline INFORMAÇOES BASSICAS & IMPORTÂNCIA \\
\hline 1. Sócio-econômicas & \\
\hline $\begin{array}{l}\text { 1.1 área: peculiaridades geo- } \\
\text { gráficas e climáticas, vias } \\
\text { de comunicação, meios de } \\
\text { transporte, mapas, zonea- } \\
\text { mento urbano e sanitário; }\end{array}$ & $\begin{array}{l}\text { 1.1 - conhecer a realidade geográ- } \\
\text { fica para avaliar a influência } \\
\text { exercida pelo meio físico e } \\
\text { social, na saúde; } \\
\text { - facilitar o planejamento das } \\
\text { atividades de visitação; } \\
\text { - adotar normas, procedimen- } \\
\text { tos, rotinas de trabalho, tipo } \\
\text { de equipamento, indumentá- } \\
\text { ria, de acordo; }\end{array}$ \\
\hline $\begin{array}{l}\text { 1.2 - população: densidade, } \\
\text { crescimento, divisão por } \\
\text { grupos etários; por sexo, } \\
\text { nacionalidade, procedên- } \\
\text { cia, profissão, ocupação, } \\
\text { organização social, carac- } \\
\text { terísticas da família e de } \\
\text { outros grupos sociais, con- } \\
\text { dições educacionais, pa- } \\
\text { drões culturais, crenças, } \\
\text { superstições, práticas de }\end{array}$ & $\begin{array}{l}\text { 1.2 - conhecer o número de pes- } \\
\text { soas a serem atendidas nos } \\
\text { diferentes grupos etários a } \\
\text { fim de planejar as atividades } \\
\text { em termos de vulnerabilida- } \\
\text { de, de cobertura, etc.; } \\
\text { - ter idéia de como os padrões } \\
\text { culturais e as relações so- } \\
\text { ciais podem estar refletindo } \\
\text { na saúde dos indivíduos e } \\
\text { na atuação da enfermagem }\end{array}$ \\
\hline
\end{tabular}

* Adaptado de: OPAS/OMS - Informe del Seminário sobre servicios de enfermería - Informe de Enfermería n. 3. Washington, OPAS, 1963. 


\begin{tabular}{|c|c|}
\hline INFORMAÇÕES BASSICAS & IMPORTÂNCIA \\
\hline $\begin{array}{l}\text { saúde, canais de comuni- } \\
\text { cação e liderança, religião, } \\
\text { renda; }\end{array}$ & $\begin{array}{l}\text { na comunidade, utilizar ade- } \\
\text { quadamente os canais de co- } \\
\text { municação e liderança em } \\
\text { favor da educação para a } \\
\text { saúde; }\end{array}$ \\
\hline $\begin{array}{l}1.3 \text { - recursos e agências sociais } \\
\text { da comunidade: número, } \\
\text { objetivos, funcionamento; }\end{array}$ & $\begin{array}{l}\text { 1.3 - manter entrosamento, utili- } \\
\text { zar e orientar as famílias na } \\
\text { utilização adequada dos re- } \\
\text { cursos familiares e da comu- } \\
\text { nidade; }\end{array}$ \\
\hline $\begin{aligned} 1.4 \text { - necessidades e problemas } \\
\text { sentidos pela população. }\end{aligned}$ & $\begin{array}{l}\text { 1.4 - verificar até que ponto a co- } \\
\text { munidade está consciente de } \\
\text { seus problemas de saúde; } \\
\text { como contribuirá para a so- } \\
\text { lução dos mesmos e quais } \\
\text { que a enfermagem deverá } \\
\text { dar prioridade. }\end{array}$ \\
\hline 2. Sanitárias & \\
\hline $\begin{array}{l}\text { 2.1 - indicadores de saúde: coe- } \\
\text { ficientes de mortalidade e } \\
\text { de morbidade por grupos } \\
\text { etários, condições de sa- } \\
\text { neamento relativos ao tra- } \\
\text { tamento da água, disposi- } \\
\text { ção de excretas e lixo e } \\
\text { das habitações em geral; }\end{array}$ & $\begin{array}{l}\text { 2.1 - conhecer a importância e } \\
\text { magnitude do problema de } \\
\text { saúde, estabelecer priorida- } \\
\text { des, planejar as atividades } \\
\text { em termos de vulnerabilida- } \\
\text { de, adotar normas e procedi- } \\
\text { mentos de acordo, progra- } \\
\text { mar, executar e avaliar efe- } \\
\text { tivamente as atividades de } \\
\text { enfermagem; }\end{array}$ \\
\hline
\end{tabular}




\begin{tabular}{|c|c|}
\hline INFORMAÇŌES BÁSICAS & IMPORTÂNCIA \\
\hline $\begin{array}{l}2.2 \text { - serviços: legislação sanitá- } \\
\text { ria, programas de saúde, } \\
\text { relação das instituições e } \\
\text { agências de saúde que } \\
\text { fornecem serviços, fun- } \\
\text { cionamento, coordenação } \\
\text { entre elas; }\end{array}$ & $\begin{array}{l}2.2 \text { - } \\
\text { manter entrosamento, utili- } \\
\text { zar e fomentar a utilização } \\
\text { correta pela população; }\end{array}$ \\
\hline $\begin{array}{l}2.3 \text { - recursos humanos já dis- } \\
\text { poníveis: pessoal médico } \\
\text { de enfermagem disponível } \\
\text { e outros profissionais da } \\
\text { equipe de saúde, suas fun- } \\
\text { ções, atribuições, número, } \\
\text { horário de trabalho, etc; }\end{array}$ & $\begin{array}{l}2.3 \text { - programar, executar e ava- } \\
\text { liar o programa de enferma- } \\
\text { gem utilizando racionalmen- } \\
\text { te os recursos disponiveis; }\end{array}$ \\
\hline $\begin{array}{l}2.4 \text { - recursos materiais já dis- } \\
\text { poniveis: planta física, } \\
\text { equipamento, material. }\end{array}$ & $\begin{array}{l}2.4 \text { - programar, executar e ava- } \\
\text { liar o programa de enferma- } \\
\text { gem utilizando racionalmen- } \\
\text { te os recursos disponiveis. }\end{array}$ \\
\hline
\end{tabular}




\begin{abstract}
ANEXO 2
ROTEIRO PARA ELABORAÇÃO DO PROGRAMA DE ENFERMAGEM E ORGANIZAÇÃO DO SERVIÇO DE VISITAÇÃO DOMICILIÁRIA
\end{abstract}

1. Elaboração do programa por escrito tendo como base os dados do levantamento.

1.1 - Título.

1.2 - Objetivo geral.

1.3 - Objetivos específicos.

1.4 - Atividades:

1.4.1 - definições;

1.4.2 - ações componentes;

1.4 .3 - normas:

- prioridades,

- concentração,

- cobertura,

- volume,

- atendimento.

1.5 - Estimativa de pessoal e material necessários.

2. Estruturação do serviço.

2.1 - Funções e atribuições do pessoal.

2.2 - Estrutura organizacional.

2.3 - Programa de treinamento de pessoal:

2.3.1 - objetivos;

2.3.2 - métodos;

2.3.3 - supervisão e avaliação.

3. Aprovação do programa.

4. Implantação.

4.1 - Instalação do equipamento e material na área física.

4.2 - Recrutamento, seleção e treinamento de pessoal.

4.3 - Divulgação do programa.

4.4 - Execução. 
ANEXO 3

MODELO DE ROTEIRO DE AVALIAÇÃO DE VISITA DOMICILIÁRIA

\begin{tabular}{|c|c|c|c|c|c|}
\hline Fases da V.D. & Pontos importantes a observar & Bom & Regular & Mau & Obs. \\
\hline Planejamento & $\begin{array}{l}\text { 1. Seleção da Visita } \\
1.1 \text { Prioridades } \ldots \ldots \ldots \ldots \\
1.2 \text { Horário } \ldots \ldots \ldots \ldots \\
1.3 \text { Itinerário } \ldots \ldots \ldots \ldots \\
\text { 2. Coleta de dados } \ldots \ldots \ldots \ldots \\
\text { 3. Prioridades da V.D. } \ldots \ldots \\
\text { 4. Revisão de conhecimentos } \\
\text { 5. Plano } \\
\text { 5.1 Objetivos } \ldots \ldots \ldots \ldots \\
\text { 5.2 Atividades } \ldots \ldots \ldots \\
\text { 6. Preparo do material } \ldots \ldots\end{array}$ & & & & \\
\hline Execução & 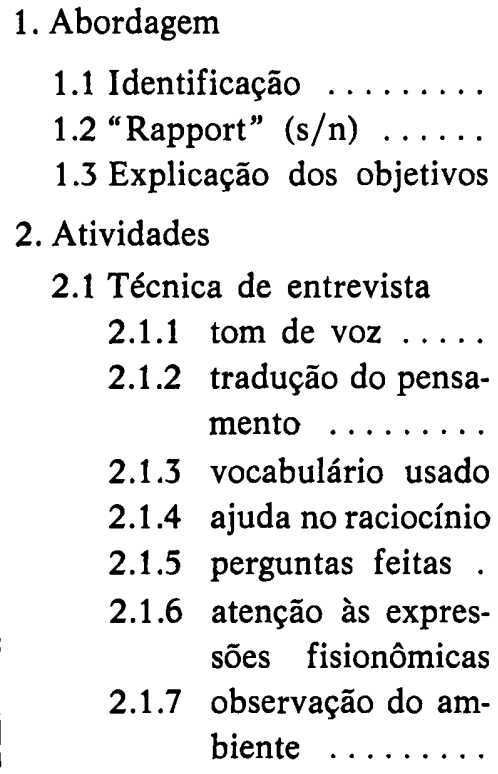 & & & & \\
\hline
\end{tabular}




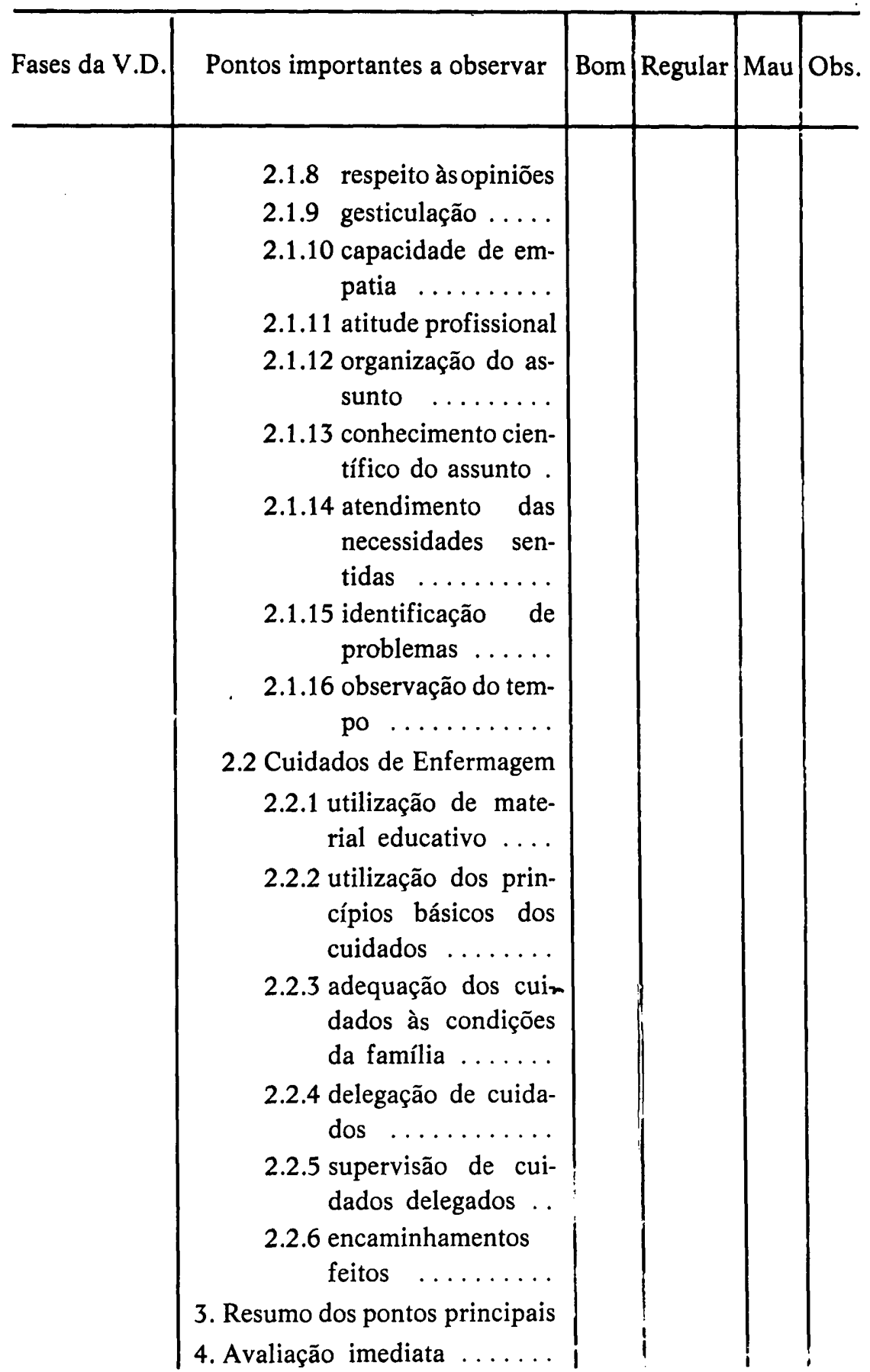




\begin{tabular}{|c|c|c|c|c|c|}
\hline Fases da V.D. & Pontos importantes a observar & Bom & Regular & Mau & Obs. \\
\hline \multirow[t]{2}{*}{$\begin{array}{l}\text { Registro de } \\
\text { dados }\end{array}$} & $\begin{array}{l}\text { 1. Objetividade } \ldots \ldots \ldots \ldots \\
\text { 2. Clareza } \ldots \ldots \ldots \\
\text { 3. Continuidade } \ldots \ldots \ldots \ldots \\
\text { 4. Seqüência lógica } \ldots \ldots \ldots \\
\text { 5. Informação à equipe } \ldots \ldots\end{array}$ & & & & \\
\hline & TOTAL DE PONTOS & & & & \\
\hline
\end{tabular}

Para uso deste roteiro:

1. Conte quantos itens foram observados como bons, regulares e maus e anote na linha correspondente a "total de pontos".

2. Atribua aos itens os seguintes pesos:

BOM -3 pontos

REGULAR - 2 pontos

MAU $\quad-1$ ponto

3. Multiplique os números de pontos pelos pesos acima, some e divida pelo número total de itens observados.

4. Compare a média obtida com a seguinte escala:

1,0 a $1,5:$ má visita

1,6 a 2,4 : visita regular

2,5 a 3,0 : boa visita

5. NOTA: preencha somente os itens observados e anote na coluna "observações" as observações pertinentes ao item.

Nome do visitador

Nome do observador

Data 